\title{
Schirmer's Test I and Determination of Intraocular Pressure in Healthy Common Buzzards (Buteo buteo)
}

\author{
Rahime Yaygingül', Zeynep Bozkan'1, Osman Bulut'², Eser Çakmakçi' \& Ali Belge
}

\begin{abstract}
Background: The structure of the eye in wild birds is $45 \%$ larger than that in humans, which provides excellent visual capacity but also makes them vulnerable to eye trauma. Trauma, neoplasia, infectious diseases of the ocular surface, uveitis, glaucoma, and corneal diseases in wild birds, but mainly trauma, can cause a reduction in their tear production; therefore, determining the amount of tear production in the wild birds is very important. Studies have shown that the results of the Schirmer's tear test (STT) and intraocular pressure (IOP) values differ among wild bird species, and that both anesthesia and sedation affects these parameters. The main objective of the present study was to determined IOP and STT I values in healthy common buzzards (Buteo buteo).

Materials, Methods \& Results: Thirty healthy common buzzards were selected for the study following clinical and ophthalmic examinations. Following physical and clinical examinations of all subjects, routine ophthalmologic examinations were conducted, including reflex examinations (pupillary, palpebral, menace, dazzle) and direct ophthalmoscopy for the eyelids, conjunctiva, cornea, iris, lens, and fundus. All examinations were conducted without anesthesia or sedation while the birds were in the dorsal recumbent position, and the results of STT I and IOP were recorded. Both tests were repeated for the right and left eyes. The mean \pm SE STT I values for the right and left eyes were $12.63 \pm 0.51$ and $12.43 \pm 0.54$ $\mathrm{mm} / \mathrm{min}$, respectively. A comparison between STT I values of the right and left eyes revealed no statistically significant differences $(P>0.620)$. The means and ranges of the TonoVet ${ }^{\circledR}$ IOP results for the right and left eyes were $32.06 \pm 1.58$ and $32.60 \pm 1.51 \mathrm{mmHg}$, respectively. There was no statistically significant difference between the results of the test on the two eyes $(P>0.05)$.

Discussion: Tear production is either increased or decreased in wild birds as a result of several types of eye diseases or trauma $(1,6)$. The most common method by which to determine tear production is either STT I (3), which is conducted without topical anesthesia, or STT II, which is conducted with topical anesthesia. As in our study, previous studies have used STT I as their method by which to determine tear production of wild birds. In a study conducted on 20 common buzzards, STT I values were $12.47 \pm 2.66 \mathrm{~mm} / \mathrm{min}$. In our study using 30 common buzzards, the STT I value was $12.63 \pm 0.51 \mathrm{~mm} /$ $\min$ for the right eye and $12.43 \pm 0.54 \mathrm{~mm} / \mathrm{min}$ for the left eye. There was no statistically significant difference between the results of the tests on the two eyes. In previous study with 25 common buzzards, IOP measured rebound tonometry was 5-30 (35-60). In our study, rebound tonometry results for IOP of 30 common buzzards were $32.06 \pm 1.58 \mathrm{mmHg}(16-47)$ for the right eye and $32.60 \pm 1.51 \mathrm{mmHg}(17-50)$ for the left eye. There was no statistically significant difference in IOP values between right and left eyes. Given that there are few studies on tear production and IOP in common buzzard, we believe that the results of this study will provide valuable new information to the literature.
\end{abstract}

Keywords: Buteo buteo, eye, STT I, rebound tonometry, TonoVet ${ }^{\circledR}$.

DOI: $10.22456 / 1679-9216.96108$

${ }^{1}$ Veterinary Faculty, Department of Surgery, Adnan Menderes University, Aydin, Turkey. ${ }^{2}$ Department of Surgery, Milas Veterinary Faculty, Muğla Sitkı Koçman University Muğla, Turkey. CORRESPONDENCE: R. Yaygıngül [ryaygingul@ hotmail.com]. Department of Surgery, Faculty of Veterinary, Adnan Menderes University. Isikli. 09017 Aydin, Turkey. 


\section{INTRODUCTION}

The structure of the eye in wild birds is $45 \%$ larger than that in humans, which provides excellent visual capacity but also makes them vulnerable to eye trauma [6]. Trauma, neoplasia, infectious diseases of the ocular surface, uveitis, glaucoma, and corneal diseases in wild birds, but mainly trauma, can cause a reduction in their tear production; therefore, determining the amount of tear production in the wild birds is very important [1]. Schirmer's tear test (STT), referred to as either STT I or STT II for the test without or with topical anesthesia [3], respectively, is the most common method by which to determine tear amount [13]. The test is conducted by determining the amount of wetness found on a 35-mm filter paper after placing it on the lateral one-third of the lower eyelid [13]. Intraocular pressure (IOP) is another important parameter used to evaluate eye diseases in birds, such as glaucoma and uveitis [19]. Two types of measurement methods applanation and rebound tonometry each of which requires a different type of device are used to measure IOP [8]. Rebound tonometry is the commonly preferred method in veterinary medicine because of its practicality and because no topical anesthetic is needed, and the TonoVet@ rebound tenometer, which has a magnetic probe on its tip, is used for this procedure [12]. The measurement is conducted by first moving the probe onto the cornea of the eye and calculating the probe's rebound movement [10]; higher IOP results in faster rebound movement. Previous studies have shown that the STT I and IOP values are different among wild bird species [1]. The aim of the present study was to determined IOP and STT I values in healthy common buzzards (Buteo buteo).

\section{MATERIALS AND METHODS}

\section{Animals}

Thirty ophthalmologically healthy common buzzards were brought to our clinic to be used in this study. Following physical and clinical examinations of all subjects, routine ophthalmologic examinations were conducted, including reflex examinations (pupillary, palpebral, menace, dazzle) and direct ophthalmoscopy for the eyelids, conjunctiva, cornea, iris, lens, and fundus. All examinations were conducted without anesthesia or sedation while the birds were in the dorsal recumbent position.

\section{Schirmer's tear test I (STT I)}

STT I was conducted on both the right and left eyes. A commercial filter paper $5 \mathrm{~mm}$ wide and $35 \mathrm{~mm}$ long was placed into the lateral one-third of the lower eyelid for $1 \mathrm{~min}$, after which the amount of wetness on the paper was used to calculate the STT I value.

\section{IOP measurements}

IOP measurements were conducted using a TonoVet ${ }^{1}{ }^{1}$ rebound tonometer without medication or anesthesia on both eyes in the same order as the STT I (the left eye after the right eye). All results were recorded and the birds were delivered to the ADU Kanat - Ger student community for rehabilitation.

\section{Statistical analysis}

Statistical analysis were conducted using SPSS. The study data were assessed by calculating the mean and standard error of mean (mean $\pm \mathrm{SE}$ ). Differences in mean values between IOP and STT I values for the right and left eyes were analyzed using a paired-samples t-test. For all tests, the level of statistical significance was $P<0.05$.

\section{RESULTS}

Based on the physical examinations and the results of clinical and hematological parameters, none of the birds were affected by systemic diseases and all the eyes were clinically normal. The results of STT I (Figure 1) and IOP (Figure 2) were recorded.

The mean values for STT I and IOP are provided in Table 1. The mean \pm SE STT I values for the right and left eyes were $12.63 \pm 0.51$ and $12.43 \pm 0.54$ $\mathrm{mm} / \mathrm{min}$, respectively. A comparison between STT I values of the right and left eyes revealed no statistically significant differences $(P>0.620)$.

The means and ranges of the TonoVet ${ }^{\circledR}$ IOP results for the right and left eyes were $32.06 \pm 1.58$ and $32.60 \pm 1.51 \mathrm{mmHg}$, respectively. There was no statistically significant difference between the results of the test on the two eyes $(P>0.05)$.

Table 1. Mean and ranges for Schirmer's tear test I and Intraocular pressure in the Buteo buteo.

\begin{tabular}{ccc}
\hline Ophtalmic test & right eye $^{*}$ & left eye $^{*}$ \\
\hline Schirmer tear test I & $12.63 \pm 0.51$ & $12.43 \pm 0.54$ \\
$(\mathrm{~mm} / 1 \mathrm{~min})$ & $(8-20)$ & $(8-20)$ \\
Intraocular pressure & $32.06 \pm 1.58$ & $32.60 \pm 1.51$ \\
& $(16-47)$ & $(17-50)$ \\
\hline
\end{tabular}

*Means \pm SD. 


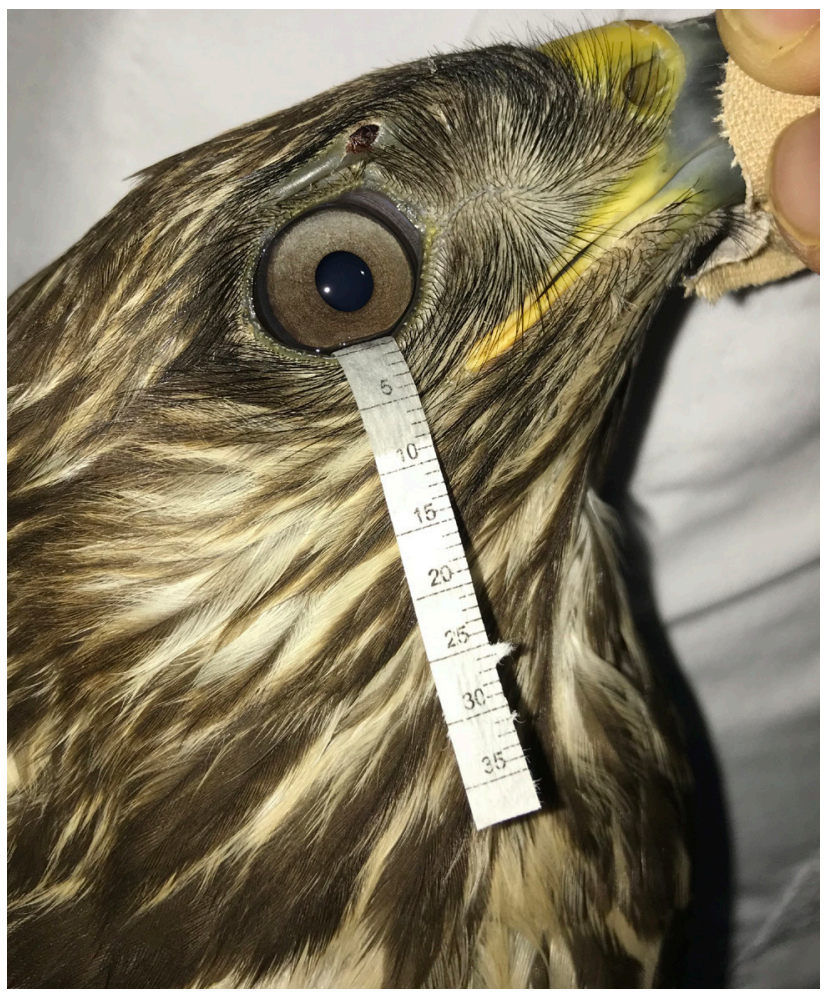

Figure 1. Schirmer tear test I in a buzzard (Buteo buteo).

\section{DISCUSSION}

With 30 subjects, our study encompassed the approximate average number of common buzzards used in previous studies on the ophthalmologic parameters in wild birds. The study conducted by Barsotti et al. [1] used 80 wild birds, of which 20 were common buzzards, and the study conducted by Reuter et al. [1] used 237 wild birds, of which 48 were common buzzards.

Tear production is either increased or decreased in wild birds as a result of several types of eye diseases or trauma $[1,6]$. The most common method by which to determine tear production is either STT I [3], which is conducted without topical anesthesia, or STT II, which is conducted with topical anesthesia [13]. As in our study, previous studies $[1-4,14]$ have used STT I as their method by which to determine tear production of wild birds. In a study conducted on 20 common buzzards, STT I values were $12.47 \pm 2.66 \mathrm{~mm} / \mathrm{min}$ [2]. In our study using 30 common buzzards, the STT I value was $12.63 \pm 0.51 \mathrm{~mm} /$ $\min$ for the right eye and $12.43 \pm 0.54 \mathrm{~mm} / \mathrm{min}$ for the left eye. There was no statistically significant difference between the results of the tests on the two eyes.

Applanation tonometry is a sensitive and reliable method by which to measure IOP, especially in small animals, and can be used in cases in which the cornea is $>9 \mathrm{~mm}$ in diameter and under topical an-

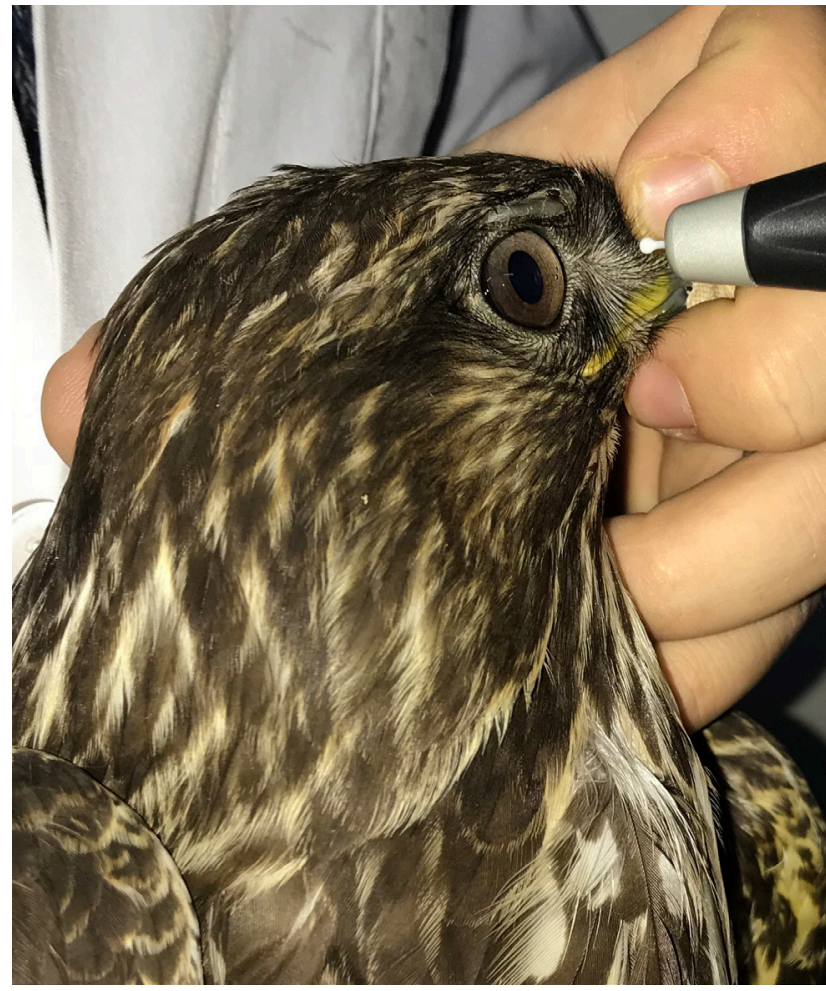

Figure 2. TonoVet ${ }^{\circledR}$ Rebound tonometer in a buzzard (Buteo buteo).

esthesia [10]; however, ocular physical factors, such as corneal weaknesses, scleral rigidity, and tear film viscosity, might affect IOP evaluation [5].

Although some studies on the amount of tears produced and IOP used only applanation tonometry [1,11], others used only rebound tonometry [9]. There are also comparative studies using both tonometry methods on birds, such as American flamingos (Phoenicopterus ruber) [7] and Eurasian Eagle owls (Bubo bubo) [5]. In the current study, rebound tonometry was used on all subjects to measure IOP.

For a reliable IOP value, six consecutive measurements are taken. The minimum and maximum values were cancelled and the remaining four measurements were averaged. The TonoVet ${ }^{\circledR}$ probe tip's contact surface with the cornea is $1.4 \mathrm{~mm}$ in diameter, does not damage the cornea, and can be used without topical anesthesia [9].

Reuter et al. [9] using 25 common buzzards have found that IOP measured using rebound tonometry was 5-30 (35-60). In our study, rebound tonometry results for IOP of 30 common buzzards were $32.06 \pm 1.58 \mathrm{mmHg}$ (16-47) for the right eye and $32.60 \pm 1.51 \mathrm{mmHg}(17$ 50 ) for the left eye. There was no statistically significant difference in IOP values between right and left eyes.

Our study aimed to determine IOP and STT I values, the most commonly used parameters for ophthalmological examinations, in common buzzards. Because of 
the limited number of studies related to the physiological eye parameters in common buzzards, we believe that our results will contribute new information to the literature.

\section{MANUFACTURER}

${ }^{1}$ Icare Finland Oy. Helsinki, Finland.

Acknowledgements. The study subjects were common buzzards supplied to the surgery clinic of the faculty in agreement with the Ministry of Forestry and Water Affairs (MFWA). We received both permission to conduct the study and ethical approval for the use of the animals from MFWA. We thankADU Kanat-Ger student community for their support and cooperation in the care and rehabilitation of these birds.

Ethical approval. The study is approved both the Adnan Menderes University (ADU) Animal Experiments Local Ethics Comittee (approvel number: 2018/49) and Turkish Republic Ministry of Forest and Water Affairs (General Directorate of Nature Conservation and National Parks [Approval no:25.02.2019/21264211-288.04])

Declaration of interest. The authors report no conflicts of interest. The authors alone are responsible for the content and writing of paper.

\section{REFERENCES}

1 Barsotti G., Briganti A., Spratte J.R., Ceccherelli R. \& Breghi G. 2013. Schirmer tear test type I readings and intraocular pressure values assessed by applanation tonometry (Tonopen ${ }^{\circledR} \mathrm{XL}$ ) in normal eyes of four European species of birds of prey. Veterinary Ophthalmology. 16(5): 365-369.

2 Cousquer G. 2005. Ophthalmological findings in free-living tawny owls (Strix aluco) examined at a wildlife veterinary hospital. Veterinary Record. 156: 734-739.

3 Featherstone H.J. \& Heinrich C. 2012. The Eye Examination and Diagnostic Procedures. In: Gelatt K.N., Gilger B.C. \& Kern T.J. (Eds). Veterinary Ophthalmology. Chapter 10. 5th edn. Ames: Wiley-Blackwell, pp.976-1060.

4 Harris M.C., Schorling J.J., Herring I.P., Elvinger F., Bright P.R. \& Pickett J.P. 2008. Ophthalmic examination findings in a colony of Screech owls (Megascops asio). Veterinary Ophthalmology. 11(3): 186-192.

5 Jeong M.B., Kim Y.J., Yi N.Y., Park S.A., Kim W.T., Kim S.E., Chae J.M., Kim J.T., Lee H. \& Seo K.M. 2007. Comparison of the rebound tonometer (TonoVet ${ }^{\circledR}$ ) with the applanation tonometer (TonoPen XL $®$ ) in normal Eurasian Eagle owls (Bubo bubo). Veterinary Ophthalmology. 10(6): 376-379.

6 Labelle A. L., Whittington J.K., Breaux C.B., Labelle P., Mitchell M.A., Zarfoss M.K., Schmidt S.A. \& Hamor R.E. 2012. Clinical utility of a complete diagnostic protocol for the ocular evaluation of free-living raptors. Veterinary Ophthalmology. 15(1): 5-17.

7 Meekins J.M., Stuckey J.A., Carpenter J.W., Armbrust L., Higbie C. \& Rankin A.J. 2015. Ophthalmic Diagnostic Tests and Ocular Findings in a Flock of Captive American Flamingos (Phoenicopterus ruber ruber). Journal Avian Medicine and Surgery. 29(2): 95-105.

8 Pacheco R.E., Bauer B.S. \& Sadar M.J. 2018. Measurement of tear production and intraocular pressure in conscious captive European fallow deer (Dama dama). The Journal of Veterinary Medical Science. 4: 227-236.

9 Reuter A., Muller K., Arndt G. \& Eule J.C. 2010. Accuracy and reproducibility of the TonoVet rebound tonometerin birds of prey. Veterinary Ophthalmology. 13(1): 80-85.

10 Reuter A., Müller K., Arndt G. \& Eule J.C. 2011. Reference intervals for intraocular pressure measured by rebound tonometry in ten raptor species and factors affecting the intraocular pressure. Journal Avian Medicine and Surgery. 25(3): 165-172.

11 Rodarte-Almeida A.C.V., Machado M., Baldotto S.B., Santos L.D.L., Lima L., Lange R.R, Froes T.R. \& MontianiFerreira F. 2013. The eye of the striped owl: morphologic observations, biometric findings and reference values for selected ophthalmic diagnostics tests. Pesquisa Veterinária Brasileira. 33(10): 1275-1289.

12 Rusanen E., Florin M., Hassig M. \& Spiess B.M. 2010. Evaluation of a rebound tonometer (Tonovet) in clinically normal cat eyes. Veterinary Ophthalmology. 13(1): 31-36.

13 Storey E.S., Carboni D.A., Kearney M.T. \& Tully T.N. 2009. Use of phenol red thread tests to evaluate tear production in clinically normal Amazon parrots and comparison with Schirmer tear test findings. Journal of the American Veterinary Medical Association. 235(10): 1181-1187.

14 Wills S., Pinard C., Nykamp S. \& Beaufrère H. 2016. Ophtalmic reference values and lesions in two captive populations of northern owls: great grey owls (Strix nebulosa) and snowy owls (Bubo scandiacus). Journal of Zoo Wildlife Medicine. 47(1): 244-255. 